\title{
DESBASTE DE MUDAS TIPO FILHOTE DO ABACAXI CV. PÉROLA - 2. ANÁLISES DE CRESCIMENTO E DE CORRELAÇÕES ${ }^{1}$
}

\author{
VALMIR PEREIRA DE LIMA², DOMINGO HAROLDO REINHARDT ${ }^{3}$ E JOÃO ALBANY COSTA ${ }^{4}$
}

\begin{abstract}
RESUMO - O abacaxi cv. Pérola, variedade mais plantada no Brasil, forma um número excessivo de mudas tipo filhote durante o mesmo período de desenvolvimento do fruto. Em plantio comercial da região do litoral Norte da Bahia, foi desenvolvido estudo com o objetivo de avaliar o efeito do desbaste de mudas tipo filhote sobre aspectos vegetativos e produtivos da cultura, desenvolvida sob condições de sequeiro. Nesta segunda parte, são apresentados os efeitos sobre o acúmulo de matérias fresca e seca nos diversos órgãos da planta e analisadas as correlações entre caracteres vegetativos e do fruto. Em delineamento em blocos completos ao acaso, em parcelas subdivididas, com sete repetições, foram estudados seis tratamentos, sendo a testemunha (sem desbaste) e cinco níveis de intensidade de desbaste de mudas tipo filhote, e três épocas de avaliação. Por meio da análise de variância, teste de comparação entre as médias e coeficientes de correlação, foram avaliados caracteres de crescimento vegetativo em pesos fresco e seco (planta inteira, raiz, caule, pedúnculo, folhas e mudas) aos 90; 120 e 150 dias após o tratamento de indução floral, e a sua correlação com caracteres do fruto. O desbaste favoreceu o acúmulo de matéria seca nas mudas tipo filhote remanescentes e na coroa do fruto, que é outro tipo de muda. A eliminação de todos os filhotes determinou a alteração da correlação entre o peso do fruto e o peso da coroa de negativa para positiva. A distribuição de matéria seca entre os órgãos mostrou partição em favor do fruto, com redução do peso seco de caule, folhas e pedúnculo na fase de maturação do fruto, a partir de 120 dias após o tratamento de indução floral.
\end{abstract}

Termos para indexação: Ananas comosus (L.) Merr., prática cultural, crescimento, partição.

\section{SLIPS THINNING FROM THE PINEAPPLE CV. PÉROLA - 2. GROWTH AND CORRELATION ANALYSES}

\begin{abstract}
Pineapple plants of the cv. Pérola, the most cultivated in Brazil, form an excessive number of slips during the same period of the fruit development. In a commercial plantation of the North Coast region of Bahia State, Brazil, was carried out a study in order to evaluate the effect of slip thinning on vegetative and productive aspects of 'Pérola' pineapple, grown without irrigation. This paper presents the results on fresh and dry matter accumulation of the different organs of the plant and discusses correlations between vegetative and fruit characters. In a completely randomized blocks design, with a split plot arrangement and seven replications, were studied six treatments represented by the control (without thinning) and five levels of intensity of slips thinning, and three dates of evaluation. By way of analyses of variance and correlation and means comparison tests were evaluated characters of vegetative growth expressed by fresh and dry matters (whole plant, roots, stem, leaves, peduncle and slips) obtained at 90, 120 and 150 days after flowering forcing, and their relationship with some fruit characters. Thinning favored the accumulation of dry matter in slips kept and in the fruit crown, which is another type of plantlet. Total removal of slips determined the change of the correlation between fruit and crown weight from a negative to a positive one. The distribution of dry matter among organs showed partition in favor of the fruit, with reduction of stem, peduncle and leaves dry matters during the fruit maturation phase, from 120 days after flowering forcing treatment.
\end{abstract}

Index terms: Ananas comosus (L.) Merril, cultural practice, growth, dry matter partition.

\section{INTRODUÇÃO}

O abacaxi é uma das frutas tropicais mais cultivadas no mundo. No Brasil, berço do abacaxizeiro e segundo maior produtor mundial, a cultura é economicamente explorada na maioria dos Estados, dando uma importante contribuição à geração de renda e emprego e, portanto, à fixação do homem no campo (Souza \& Souza, 2000).

As variedades mais cultivadas no Brasil são a 'Pérola' e a 'Smooth Cayenne', com características bem distintas. A planta da cultivar Smooth Cayenne ou Caiena Lisa, a mais importante em nível mundial, não possui espinhos ao longo das bordas das folhas, com exceção das extremidades, tem alta densidade foliar, fruto cilíndrico e gera reduzido número de mudas tipo filhote $(0 \mathrm{a}$ 4). Por outro lado, a cultivar Pérola, variedade brasileira, respondendo por cerca de $80 \%$ da produção nacional (Reinhardt $\&$ Souza, 2000), é uma planta de porte médio, com menor número de folhas dotadas de espinhos nas bordas, fruto cônico, e que produz muitos filhotes (5 a 15, segundo Cabral, 2000).

O ciclo do abacaxizeiro é dividido em três fases, a vegetativa, a reprodutiva e a de formação de mudas. Enquanto a primeira fase é bem distinta, terminando com o início da diferenciação floral ou o tratamento artificial de indução floral (TIF), as duas outras se sobrepõem por um longo período. A

1 (Trabalho 052/2000). Recebido: 20/02/2001. Aceito para publicação: 04/10/2001. Parte da dissertação de mestrado do primeiro autor (UFBA). 2 Eng0 Ag0., M. Sc., Empresa Baiana de Desenvolvimento Agrícola S.A (EBDA

3 Eng0 Agr0., PhD., Pesquisador Embrapa Mandioca e Fruticultura, C.P. 7, 44.380-000 Cruz das Almas, BA, Brasil; dharoldo@cnpmf.embrapa.br 4 Eng0 Agr0., Professor da Escola de Agronomia da UFBA, Cruz das Almas, BA, Brasil. 
partir do fechamento das últimas flores, que ocorre cerca de 90 dias após o TIF, até a colheita dos frutos, que normalmente acontece a partir de 155 a 170 dias após o TIF, há o desenvolvimento simultâneo do fruto e das mudas tipo filhote (Reinhardt, 2000). Sabendo-se que a relação fonte/dreno influi muito na distribuição e acúmulo de fotossintatos, a presença de vários importantes drenos ativos tende a estabelecer uma forte competição entre os mesmos, podendo prejudicar o tamanho e/ ou peso do fruto.

No manejo de culturas, sobretudo de fruteiras em geral, o desbaste é a prática usada para reduzir o número de drenos competidores, evitando-se a formação de frutos pequenos, de menor valor comercial. No Brasil, o desbaste de mudas de abacaxi não tem recebido atenção, nem na pesquisa nem na prática, embora, mais recentemente, tenha sido observado o seu emprego por alguns produtores dos Estados de Tocantins e Minas Gerais, em busca de melhorias da produtividade e da qualidade dos frutos.

O único trabalho publicado sobre o assunto, e a mesma cultivar, no Brasil, foi o de Giacomelli et al. (1967), feito na Estação Experimental de Limeira, que não constataram efeito significativo da redução de coroa e do desbaste de filhotes em dois níveis (total e redução para três filhotes) sobre o peso de frutos. Os resultados relatados na primeira parte deste trabalho também não indicaram efeitos com significância estatística sobre o peso do fruto e a produtividade da cultura, mas evidenciaram tendência consistente de elevação do peso do fruto por até 13\% (Lima et al., 2001), determinando uma relação benefício/custo bastante positiva para tal prática (Reinhardt et al., 2000).

Não tem sido encontrada informação na literatura, se o desbaste parcial de filhotes influi no vigor das mudas remanescentes, inclusive na coroa do fruto, aspecto também relevante sob o ponto de vista prático, pois os filhotes constituem o principal material de plantio da cv. Pérola. A eliminação de algumas mudas em estádio inicial do seu desenvolvimento provavelmente favorecerá o crescimento e o vigor das demais mudas da mesma planta.

O estudo visou aavaliar o efeito do desbaste de mudas tipo filhote sobre aspectos vegetativos e produtivos do abacaxi cv. Pérola, cultivado sob as condições de sequeiro do ecossistema dos tabuleiros costeiros, no litoral Norte da Bahia. Nesta segunda parte do trabalho, são apresentados e discutidos os resultados relativos ao acúmulo de matéria fresca e seca nos diferentes órgãos da planta e as correlações entre caracteres vegetativos e do fruto.

\section{MATERIAL E MÉTODOS}

O experimento foi conduzido em abacaxizal comercial da Fazenda Agropecuária Gavião Ltda, no município de Entre Rios, Bahia, Brasil, situada no Tabuleiro Costeiro, Zona da Mata, na região do Litoral Norte, no período de junho de 1997 a dezembro de 1998. O plantio apresentou sistema de filas duplas, com espaçamento de $0,80 \mathrm{~m} \times 0,40 \mathrm{~m} \times 0,30 \mathrm{~m}$, correspondendo a 55550 plantas $\mathrm{ha}^{-1}$.

Em delineamento de blocos completos ao acaso, em parcelas subdivididas, com sete repetições, foram estudados os seguintes tratamentos de desbaste de mudas tipo filhote, efetuado aos 90 dias após o tratamento de indução floral: 1 todas as mudas desbastadas; 2 - mantidas duas mudas do lado do sol poente; 3 - mantidas quatro mudas, com desbaste, de cima para baixo; 4 - mantidas quatro mudas, com desbaste, de baixo para cima; 5 - mantidas seis mudas; 6 - sem desbaste (testemunha), em três épocas de avaliação. Cada parcela ocupou área de $32,4 \mathrm{~m}^{2}$ com 94 plantas, sendo 60 úteis, distribuídas entre duas fileiras duplas com 15 plantas por fileira, além de bordaduras de fileiras simples de cada lado e pelo menos uma planta nas extremidades de cada fileira.

Informações detalhadas sobre as condições edafoclimáticas, preparo do solo, manejo do plantio e práticas culturais foram apresentadas na primeira parte do trabalho (Lima et al., 2001).

Para avaliar o crescimento vegetativo da planta, foram feitas três coletas aos 90; 120 e 150 dias após o tratamento de indução floral, sendo uma planta por unidade experimental, e determinados os pesos fresco (planta inteira, raiz, caule, pedúnculo, folhas e mudas) e seco (raiz, caule, pedúnculo, folhas e mudas), após secagem por sete dias na estufa a $80^{\circ} \mathrm{C}$. Todos os frutos da área útil foram colhidos e pesados. Três frutos da área útil de cada unidade experimental foram a amostra usada para a determinação de variáveis de qualidade do fruto e da coroa.

Os dados obtidos foram submetidos a análises de variância e correlação pelo Sistema de Análises de Engenharia e Genética-SAEG, comparando-se as médias pelo teste de Tukey, a $5 \%$ de probabilidade.

\section{RESULTADOS E DISCUSSÃO}

Análise de crescimento vegetativo - Os tratamentos de desbaste estudados não apresentaram efeito significativo sobre o acúmulo de pesos fresco (Tabela 1) e seco (Tabela 2) da planta inteira, bem como dos seus órgãos (raízes, caule, folhas, pedúnculo). No entanto, houve diferenças significativas para os pesos fresco e seco do conjunto de mudas tipo filhote presentes em cada planta, o que era esperado em função das intensidades diferentes do desbaste efetuado, confirmando apenas que os tratamentos foram corretamente aplicados. Ficou também evidenciada a significância estatística do fator período para as variáveis peso fresco (pedúnculo, folhas e mudas) e peso seco (caule, pedúnculo, folhas e mudas), indicando variações significativas em função da data de avaliação (90; 120 e 150 dias após o tratamento de indução floral). Por outro lado, a interação entre os fatores estudados não foi significativa, não tendo ocorrido variação de significância do efeito dos tratamentos em função do período de avaliação.

Em geral, o peso médio das mudas tipo filhote obtido neste estudo foi baixo (Tabela 3), o que é compatível com o peso relativamente reduzido dos frutos colhidos (peso médio geral de $810 \mathrm{~g}$ ) resultante do vigor vegetativo moderado das plantas e do estresse hídrico ocorrido na fase reprodutiva do ciclo da cultura. Apesar desse vigor vegetativo relativamente pequeno das plantas e mudas, ficou evidente um efeito favorável do desbaste com a manutenção de apenas duas mudas na planta (tratamento 2), determinando um peso médio maior por muda em todos os três períodos de avaliação, com diferença estatística significativa aos 120 e 150 dias para peso fresco (Tabela 3 ) e aos 150 dias para 
peso seco (Tabela 4). A menor diferença foi $74 \%$ para peso fresco e $68 \%$ para peso seco, na comparação dos valores médios gerais desta variável. Por outro lado, não se observou o mesmo efeito quando se reduziu o número de mudas tipo filhote mantidas na planta, em torno de dez (testemunha) para seis (tratamento 5) ou quatro (tratamentos 3 e 4). Portanto, os dados sugerem que a retirada parcial de mudas tipo filhote, em início de seu desenvolvimento, resultou numa partição mais favorável de matérias fresca e seca para as mudas, no caso do tratamento com menor número de mudas (drenos) remanescentes na planta.

A evolução do peso seco presente no caule, pedúnculo e folhas (Figura 1), ao longo do período de 90 a 150 dias após o tratamento de indução floral do abacaxizeiro cv. Pérola, foi decrescente, independentemente da intensidade do desbaste de mudas efetuado. Aos 90 dias após o TIF, o que corresponde acerca de 45 dias após o aparecimento da inflorescência na roseta foliar central da planta, os valores de matéria seca dos três órgãos foram superiores aos obtidos aos 120 e 150 dias, excetuando-se apenas o caso do peso seco das folhas e do pedúnculo no tratamento 3 (desbaste parcial, de cima para baixo, mantendo 4 mudas). A redução consistente da matéria seca destes órgãos da planta sugere que tenha havido translocação de substâncias de reserva, em primeiro lugar para o fruto e, em intensidade menor, para mudas em formação (filhotes e a coroa do fruto). No entanto, a diminuição observada para o peso médio da muda entre $120 \mathrm{e}$ 150 dias (Tabelas 3e 4) parece indicar que, nesta fase final de enchimento do fruto, até mesmo as mudas podem atuar como fontes de matéria seca para o fruto, que é o dreno principal.

Lopes et al. (1987) observaram, em feijão, a seqüência preferencial dos drenos metabólicos, iniciando com as raízes e as folhas, e após algum tempo de desenvolvimento vegetativo da planta, mudou-se para o caule, e, quando este atingiu o ganho máximo em matéria seca, iniciou-se o enchimento dos grãos, de maneira acentuada e definitiva. Nos três órgãos citados da planta do abacaxizeiro, a translocação de fotossintatos foi relativamente menor no tratamento 1 (desbaste total de mudas), com o menor número de drenos, do que no tratamento 6 (testemunha - sem desbaste), com o maior número de drenos. Todavia, parece que a remoção de drenos (mudas) não fez com que os drenos que permaneceram, tenham sido proporcionalmente favorecidos pela translocação de reservas, à exceção do tratamento 2 , no qual as duas mudas mantidas após o desbaste apresentaram maior peso médio em função do acúmulo de matéria seca (Tabelas 3 e 4).

Coeficientes de correlação - Os dados sobre o crescimento vegetativo do abacaxizeiro cv. Pérola, determinado por meio dos pesos frescos (Tabela 5) e secos (Tabela 6) acumulados, até 90; 120 e 150 dias após o tratamento de indução floral, indicam uma associação estreita e positiva entre a planta inteira e os seus órgãos (raiz, caule, pedúnculo, folhas, mudas), com coeficientes de correlação significativos no nível de $1 \%$ de probabilidade entre todos os caracteres. Os coeficientes foram mais elevados para as correlações entre planta, caule, folhas e pedúnculo, e mais baixos para as correlações entre raízes e os demais órgãos da planta. Como esperado, plantas com pesos maiores para raízes, caule e folhas determinaram também um maior acúmulo de matérias fresca e seca nas mudas, independentemente do desbaste parcial das mudas realizado em alguns tratamentos deste estudo.

Por outro lado, as correlações entre caracteres físicos, químicos e físico-químicos do fruto foram distintas para as diversas variáveis, tendo algumas delas sido influenciadas pelos tratamentos de desbaste estudados (Tabela 7). Os coeficientes gerais de correlação indicaram que o peso médio do fruto guarda associação positiva e altamente significativa com as variáveis de comprimento e diâmetro do fruto com magnitude de $0,9519 \mathrm{e}$ 0,5927, respectivamente, ocorrendo correlação negativa significativa entre o teor de sólidos solúveis totais (SST) e a acidez total titulável (ATT) do fruto, embora com magnitude mais baixa $(-0,3809)$. E estas correlações não foram afetadas pelos tratamentos de desbaste, salvo um valor não significativo observado para a correlação entre peso e diâmetro do fruto dentro do tratamento 3.

Correlações positivas entre peso e dimensões do fruto são esperadas, o mesmo ocorrendo para a associação negativa entre SST e ATT, pois o próprio processo de maturação do fruto implica transformação de ácidos em açúcares. Cabral et al. (1988), Reinhardt \& Medina (1992) e Carvalho (1999) também constataram teores mais altos de STT em frutos com menor ATT. As correlações do peso do fruto com os pesos frescos da planta e das folhas (Tabela 7) foram positivas e significativas para todos

TABELA 1 - Quadrados médios da análise de variância para os pesos frescos (g) da planta inteira, raízes, caule, pedúnculo, folhas e mudas do abacaxi cv. Pérola em resposta ao desbaste de mudas tipo filhote. Entre Rios-BA, 1998.

\begin{tabular}{|c|c|c|c|c|c|c|c|}
\hline \multirow{2}{*}{$\begin{array}{l}\text { Causas de } \\
\text { Variação }\end{array}$} & \multirow[t]{2}{*}{ G. L } & \multicolumn{6}{|c|}{ Peso fresco $(\mathrm{g})$} \\
\hline & & Planta inteira ${ }^{1}$ & Raízes ${ }^{2}$ & Caule ${ }^{1}$ & Pedúnculo ${ }^{1}$ & Folh as ${ }^{1}$ & $\mathrm{Mudas}{ }^{2}$ \\
\hline Blocos & 6 & $0,4424^{* *}$ & $0,0529^{*}$ & $0,6940^{* *}$ & $0,6206^{* *}$ & $0,3845^{* *}$ & $0,6717^{* *}$ \\
\hline Tratamentos $(\mathrm{T})$ & 5 & $0,0889^{\mathrm{ns}}$ & $0,0377^{\mathrm{ns}}$ & $0,1215^{\mathrm{ns}}$ & $0,0970^{\mathrm{ns}}$ & $0,1073^{\mathrm{ns}}$ & $1,7607^{* *}$ \\
\hline Resíduo (A ) & 30 & 0,0515 & 0,0184 & 0,0631 & 0,0517 & 0,0571 & 0,0881 \\
\hline Perío do (P) & 2 & $0,0335^{\mathrm{ns}}$ & $0,0277^{\mathrm{ns}}$ & $0,0648^{\mathrm{ns}}$ & $0,1057^{* *}$ & $0,2444^{* *}$ & $0,1081^{*}$ \\
\hline $\mathrm{P} \times \mathrm{T}$ & 10 & $0,0204^{\mathrm{ns}}$ & $0,0158^{\mathrm{ns}}$ & $0,0295^{\mathrm{ns}}$ & $0,0137^{\mathrm{ns}}$ & $0,0254^{\mathrm{ns}}$ & $0,0191^{\mathrm{ns}}$ \\
\hline Resíd uo (B) & 72 & 0,0248 & 0,0120 & 0,0329 & 0,0166 & 0,0255 & 0,0335 \\
\hline C. V. $(\%)$ & & 4,77 & 7,87 & 8,22 & 6,35 & 5,34 & 11,79 \\
\hline M édia geral & & 2319,6 & 16,1 & 195,4 & 124,4 & 1123,0 & 209,7 \\
\hline
\end{tabular}


TABELA 2 - Quadrados médios da análise de variância para pesos secos (g) das raízes, caule, pedúnculo, folhas e mudas do abacaxizeiro cv. Pérola em resposta ao desbaste de mudas tipo filhote. Entre Rios-BA, 1998.

\begin{tabular}{|c|c|c|c|c|c|c|}
\hline \multirow{2}{*}{$\begin{array}{l}\text { Causas de } \\
\text { Variação }\end{array}$} & \multirow[t]{2}{*}{ G. L } & \multicolumn{5}{|c|}{ Peso seco $(\mathrm{g})$} \\
\hline & & Raízes $^{2}$ & $\mathrm{Caule}^{2}$ & Pedúnculo ${ }^{2}$ & Folhas $^{1}$ & $\mathrm{Mudas}^{2}$ \\
\hline Blocos & 6 & $0,0309^{*}$ & $0,6340^{* *}$ & $0,2351^{* *}$ & $0,3316^{* *}$ & $0,6717^{* *}$ \\
\hline Tratamentos $(\mathrm{T})$ & 5 & $0,0230^{\mathrm{ns}}$ & $0,0881^{\mathrm{ns}}$ & $0,0314^{\mathrm{ns}}$ & $0,0820^{\mathrm{ns}}$ & $1,7607^{* *}$ \\
\hline Resíduo (A ) & 30 & 0,0144 & 0,0464 & 0,0197 & 0,0465 & 0,0881 \\
\hline Perío do (P) & 2 & $0,0074^{\mathrm{ns}}$ & $0,3093^{* *}$ & $0,0822^{* *}$ & $0,1064^{*}$ & $0,1081^{*}$ \\
\hline $\mathrm{P} \times \mathrm{T}$ & 10 & $0,0119^{\mathrm{ns}}$ & $0,0173^{\mathrm{ns}}$ & $0,0087^{\mathrm{ns}}$ & $0,0151^{\mathrm{ns}}$ & $0,0191^{\mathrm{ns}}$ \\
\hline Resíduo (B) & 72 & 0,0080 & 0,0249 & 0,0078 & 0,0240 & 0,0335 \\
\hline C. V. $(\%)$ & & 6,97 & 9,11 & 6,00 & 6,69 & 11,79 \\
\hline Média geral & & 10,03 & 55,27 & 21,5 & 234,71 & 43,52 \\
\hline
\end{tabular}

$\left({ }^{*}\right)$ : significativo no nível de $1 \%$ de probabilidade $;\left(^{*}\right)$ : significativo no nível de $5 \%$ de probabilidade; ns : não significativo, mediante teste $\mathrm{F}$; ${ }^{1}$ Dados transformados em log.X; ${ }^{2}$ Dados transformados em $\log (\mathrm{X}+10)$.

TABELA 3 - Influência do desbaste de mudas tipo filhote, sobre os pesos frescos médios por muda (g) em plantas do abacaxi cv. Pérola, aos 90; 120 e 150 dias após o tratamento de indução floral (TIF). Entre Rios-BA, 1998.

\begin{tabular}{|c|c|c|c|c|}
\hline \multirow[t]{2}{*}{ Tratamentos } & \multicolumn{4}{|c|}{ Dias após o TIF } \\
\hline & 90 & 120 & 150 & Média \\
\hline 1. Desbaste total dos filhotes & -- & -- & -- & -- \\
\hline 2. Desbaste parcial, mantendo 2 mudas & $60,5 \mathrm{Aa}$ & $103,5 \mathrm{Aa}$ & $85,5 \mathrm{Aa}$ & 83,2 \\
\hline $\begin{array}{l}\text { 3. Desbaste parcial, de cima para baixo, } \\
\text { mantendo } 4 \text { mudas }\end{array}$ & $34,0 \mathrm{Aa}$ & $48,5 \mathrm{Ba}$ & $61,0 \mathrm{ABa}$ & 47,8 \\
\hline $\begin{array}{l}\text { 4. Desbaste parcial, de baixo para cima, } \\
\text { mantendo } 4 \text { mudas }\end{array}$ & $37,7 \mathrm{Aa}$ & $52,2 \mathrm{Ba}$ & $47,0 \mathrm{ABa}$ & 45,6 \\
\hline 5. Desbaste parcial, mantendo 6 mudas & $42,8 \mathrm{Aa}$ & $41,6 \mathrm{Ba}$ & $51,0 \mathrm{ABa}$ & 45,1 \\
\hline 6. Testemunha - sem desbaste & $48,3 \mathrm{Aa}$ & $55,1 \mathrm{Ba}$ & $30,6 \mathrm{Ba}$ & 44,7 \\
\hline Média & 44.7 & 60.2 & 55.0 & 53.3 \\
\hline D.M.S. & 60,9 & 41,2 & 38,7 & \\
\hline
\end{tabular}

TABELA 4 - Influência do desbaste de mudas tipo filhote, sobre os pesos secos médios por muda (g) em plantas do abacaxi cv. Pérola, aos 90; 120 e 150 dias após o tratamento de indução floral (TIF). Entre Rios-BA, 1998.

Tratamentos

Dias após o TIF

\begin{tabular}{lcccc} 
& 90 & 120 & 150 & Média \\
\hline 1. Desbaste total dos filhotes & -- & -- & -- & -- \\
2. Desbaste parcial, mantendo 2 mudas & $17,1 \mathrm{Aa}$ & $19,6 \mathrm{Aa}$ & $12,9 \mathrm{Aa}$ & 16,5 \\
$\begin{array}{l}\text { 3. Desbaste parcial, de cima para baixo, } \\
\text { mantendo 4 mudas }\end{array}$ & $9,8 \mathrm{Aa}$ & $8,9 \mathrm{Aa}$ & $9,1 \mathrm{ABa}$ & 9,3 \\
$\begin{array}{l}\text { 4. Desbaste parcial, de baixo para cima, } \\
\text { mantendo 4 mudas }\end{array}$ & $11,5 \mathrm{Aa}$ & $10,1 \mathrm{Aa}$ & $7,1 \mathrm{ABa}$ & 9,6 \\
5. Desbaste parcial. mantendo 6 mudas & $13.6 \mathrm{Aa}$ & $7.8 \mathrm{Aa}$ & $7.9 \mathrm{ABa}$ & 9.8 \\
6. Testemunha - sem desbaste & $12.6 \mathrm{Aa}$ & $10.7 \mathrm{Aa}$ & $4.8 \mathrm{Ba}$ & 9.4 \\
Média & 12,9 & 11,4 & 8,4 & 10.9 \\
D.M.S. & 13,4 & 13,5 & 7,7 & \\
\hline
\end{tabular}

Valores seguidos por letras maiúsculas (colunas) e minúsculas (linhas) iguais não diferem entre si, pelo teste de Tukey $(\mathrm{P}>0,05)$. 
TABELA 5 - Coeficientes de correlação entre caracteres de crescimento vegetativo (peso fresco) do abacaxi cv. Pérola. Entre Rios-BA, 1998.

\begin{tabular}{lccccc}
\hline \multicolumn{1}{c}{ Caracteres } & Raiz & Caule & Pedúnculo & Folhas & M udas \\
\hline Planta inteira & $0,4588^{* *}$ & $0,9495^{* *}$ & $0,9268 * *$ & $0,9447 * *$ & $0,7261 * *$ \\
Raiz & & $0,5073^{* *}$ & $0,4581^{* *}$ & $0,3969^{* *}$ & $0,4184 * *$ \\
Caule & & $0,9167 * *$ & $0,9424 * *$ & $0,6112 * *$ \\
Pedúnculo & & & $0,9014 * *$ & $0,6517 * *$ \\
Folhas & & & & $0,5654 * *$ \\
\hline
\end{tabular}

TABELA 6 - Coeficientes de correlação entre caracteres de crescimento vegetativo (peso seco) do abacaxi cv. Pérola. Entre Rios-BA, 1998.

\begin{tabular}{lccccc}
\hline \multicolumn{1}{c}{ Caracteres } & Raiz & Caule & Pedúnculo & Folhas & M udas \\
\hline P lanta inteira & $0,4638^{* *}$ & $0,8838^{* *}$ & $0,9067^{* *}$ & $0,9347^{* *}$ & $0,7670^{* *}$ \\
Raiz & & $0,4688^{* *}$ & $0,4841^{* *}$ & $0,4614^{* *}$ & $0,4026^{* *}$ \\
C aule & & $0,9247^{* *}$ & $0,9444^{* *}$ & $0,6622^{* *}$ \\
Pedúnculo & & & $0,9238^{* *}$ & $0,7237^{* *}$ \\
Folhas & & & & $0,6716 * *$ \\
\hline
\end{tabular}

** : Significativo no nível de $1 \%$ de probabilidade, pelo teste Tukey.

TABELA 7 - Coeficientes de correlação entre caracteres do fruto e vegetativos do abacaxi cv. Pérola, em resposta ao desbaste de mudas tipo filhote. Entre Rios -BA, 1998.

\begin{tabular}{|c|c|c|c|c|c|c|c|}
\hline Caracteres & T1 & $\mathbf{T} 2$ & T3 & T4 & T5 & T 6 & Geral \\
\hline Peso x Comprimento fruto & $0,92 * *$ & $0,96 * *$ & $0,90 * *$ & $0,96 * *$ & $0,95 * *$ & $0,96 * *$ & $0,95 * *$ \\
\hline Peso fruto x Peso coroa & $0,38 *$ & $0,34^{\mathrm{ns}}$ & $-0,08^{\mathrm{ns}}$ & $0,23^{\mathrm{ns}}$ & $0,19^{\mathrm{ns}}$ & $-0,52 * *$ & $0,13^{\mathrm{ns}}$ \\
\hline Peso x Diâmetro do fruto & $0,76 * *$ & $0,96 * *$ & $0,070^{\mathrm{ns}}$ & $0,93 * *$ & $0,92 * *$ & $0,94 * *$ & $0,59 * *$ \\
\hline Comprimento fruto $\mathrm{x}$ & $0,14^{\mathrm{ns}}$ & $0,037^{\mathrm{ns}}$ & $-0,44^{*}$ & $-0,39 *$ & $-0,29^{\mathrm{ns}}$ & $-0,62 * *$ & $-0,22 * *$ \\
\hline \multicolumn{8}{|l|}{ Comprimento coroa } \\
\hline SST x Acidez do fruto & $-0,36^{\mathrm{ns}}$ & $-0,31^{\mathrm{ns}}$ & $-0,50 * *$ & $-0,42 *$ & $-0,26^{\mathrm{ns}}$ & $-0,42 *$ & $-0,38 * *$ \\
\hline Peso fruto x Peso planta & $0,49 *$ & $0,80 * *$ & $0,48 *$ & $0,73 * *$ & $0,58 * *$ & $0,67 * *$ & $0,62 * *$ \\
\hline Peso fruto $\mathrm{x}$ Peso mudas & $0,00^{\mathrm{ns}}$ & $0,75 * *$ & $0,36^{\mathrm{ns}}$ & $0,78 * *$ & $0,52 * *$ & $0,59 * *$ & $0,50^{*}$ \\
\hline Peso fruto x Peso folhas & $0,47 *$ & $0,74 * *$ & $0,39 *$ & $0,63 * *$ & $0,51 * *$ & $0,67 * *$ & $0,57 * *$ \\
\hline
\end{tabular}

* e ** : Significativos, respectivamente, nos níveis de 5\% e $1 \%$ de probabilidade, pelo teste t; ns : não significativo.

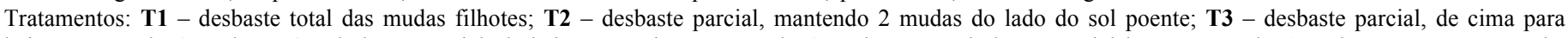

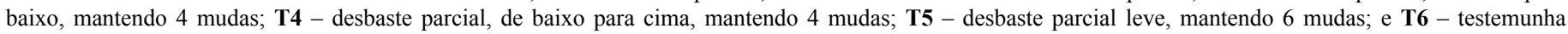
sem desbaste.

os tratamentos estudados, com coeficientes de magnitude mais baixa para o desbaste total (tratamento 1), confirmando resultados obtidos por grande número de autores, para diversas cultivares de abacaxi, destacados por Reinhardt et al. (1987) e resumidos nos livros de Py et al. (1984) e de Cunha et al. (1999). Tais associações positivas são levadas em conta nas recomendações técnicas sobre a indução floral artificial do abacaxizeiro, determinando-se a melhor época e idade da planta para a realização desta prática cultural, em função do nível mínimo de crescimento atingido pelas plantas, que possa assegurar a obtenção de frutos de peso adequado para os diferentes mercados. Plantas mais vigorosas tendem a produzir frutos mais pesados.

No entanto, as correlações de peso e comprimento do fruto com os pesos frescos de mudas e da coroa foram nitidamente influenciadas pelos tratamentos de desbaste (Tabela 7). No tratamento-testemunha, sem desbaste, maiores pesos de fruto foram obtidos em plantas com pesos de mudas (conjunto de mudas do tipo filhote) mais elevados, mas tal associação positiva 

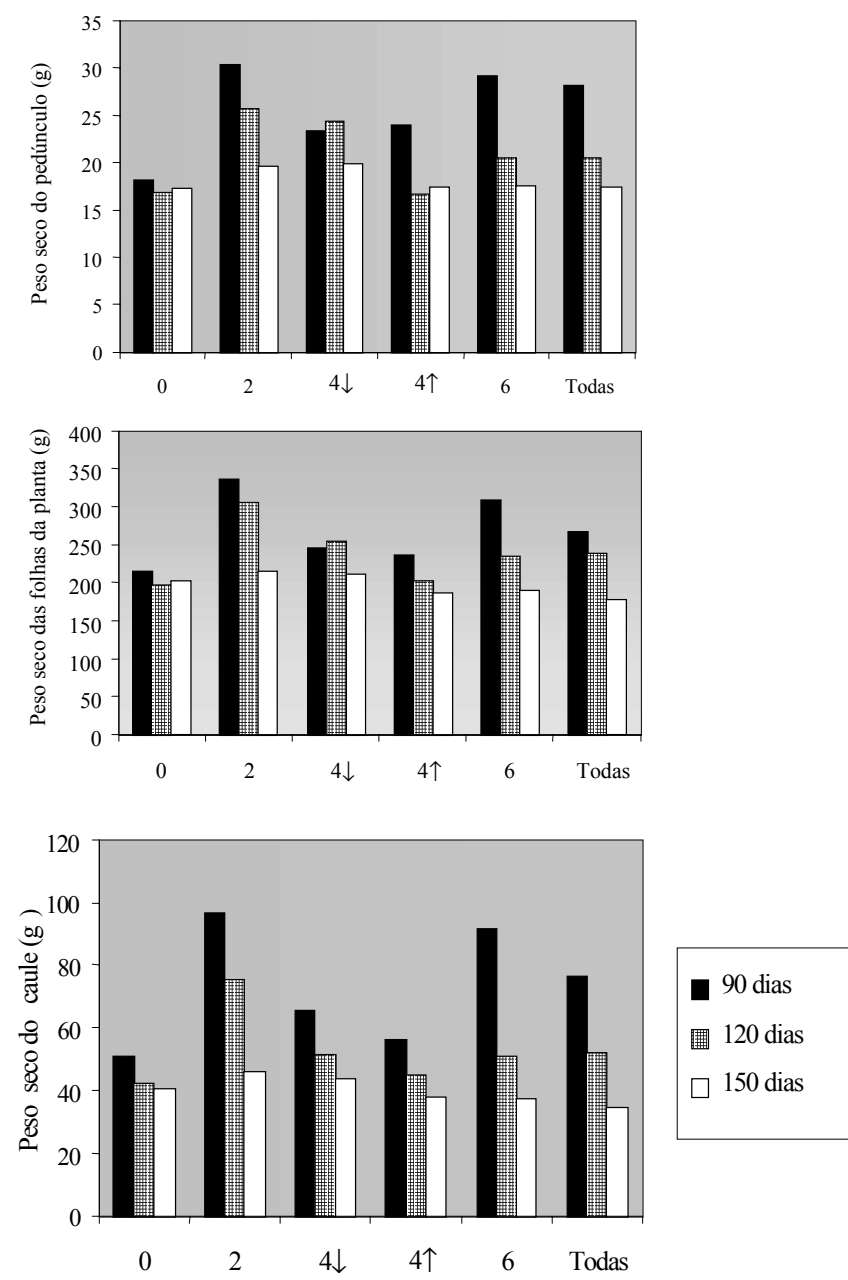

FIGURA 1 - Efeito do desbaste de mudas tipo filhote sobre o peso seco de caule, folhas e pedúnculo do abacaxizeiro cv. Pérola, em três épocas após o tratamento de indução floral. Entre Rios-BA, 1998.

não foi significativa no tratamento 3 , no qual se procedeu o desbaste parcial, mantendo-se quatro mudas de cima para baixo no pedúnculo.

$\mathrm{O}$ efeito do desbaste de mudas tipo filhote afetou mais fortemente as correlações do fruto com a coroa. A correlação foi negativa e altamente significativa, tanto para os pesos como para os comprimentos das duas variáveis, dentro do tratamentotestemunha (T6), mas foi positiva dentro de vários dos tratamentos com desbaste parcial e total estudados (Tabela 7). O contraste maior ocorreu entre testemunha e o desbaste total de mudas tipo filhote (T1). Nas plantas-testemunha (sem desbaste, com cacho completo de mudas), frutos mais pesados estiveram associados com coroas mais leves (e mais curtas), ao passo que, em plantas com desbaste total de mudas, frutos mais pesados apresentaram também coroas mais pesadas, reforçando a constatação de que a coroa passa a ser um dreno importante para os fotossintatos após a redução do número de mudas tipo filhote, na fase de desenvolvimento do fruto.

\section{CONCLUSÕES}

1. O desbaste de mudas tipo filhote favorece o acúmulo de matéria seca nas mudas remanescentes e na coroa do fruto do abacaxi cv. Pérola.

2. A distribuição de matéria seca entre os órgãos indica partição em favor do fruto, com redução do peso seco de caule, folhas e pedúnculo na fase de maturação do fruto, a partir de 120 dias após o tratamento de indução floral.

3. O desbaste de mudas determina a alteração da correlação entre peso do fruto e peso da coroa, de negativa e altamente significativa para não significativa ou até mesmo positiva e significativa, a depender da intensidade do desbaste.

4. As correlações do peso do fruto e do peso das mudas com os pesos da planta e dos seus principais órgãos são positivas e altamente significativas.

\section{REFERÊNCIAS BIBLIOGRÁFICAS}

CABRAL, J. R. S. Variedades. In: REINHARDT, D. H., SOUZA, L. F. da S., CABRAL, J. R. S. (Org.) Abacaxi. Produção: Aspectos técnicos. Cruz das almas: EMBRAPA Mandioca e Fruticultura, Brasília: Embrapa Comunicação para Transferência de Tecnologia, 2000. p.15-18; (Frutas do Brasil; 7)

CABRAL, J. R. S.; MATOS, A. P. de.; CUNHA, G. A. P. da. Caracterização morfológico-agronômica de germoplasma de abacaxi. In: CONGRESSO BRASILEIRO DE FRUTICULTURA, 9, 1988, Campinas. Anais... Campinas: SBF, 1988. v.1, p.35-40.

CARVALHO, V. D. de; CUNHA, G. A. P. da. Produtos e usos. In: CUNHA, G. A. P. da.; CABRAL, J. R. S.; SOUZA, L. F. da S.(Org.) O abacaxizeiro: cultivo, agroindústria e economia. Brasília Mandioca Fruticultura, EMBRAPA, 1999. 480p. p.389-402.

CUNHA, G. A. P. da.; CABRAL, J. R. S.; SOUZA, L. F. da S. In: CUNHA, G. A. P. da., CABRAL, J. R. S., SOUZA, L. F. da S. (Org.) O abacaxizeiro: Cultivo, agroindústria e economia. Brasília: EMBRAPA Mandioca e Fruticultura, 1999. 480p.

GIACOMELLI, E. J.; ROCHELLE, L. A.; IGUE, T. Poda da coroa e desbaste de filhotes de inflorescência e fruto novo de abacaxizeiro. Ciência e Cultura, São Paulo, v.19, n.2, p.317-318, 1967.

LIMA, V. P. de; REINHARDT, D. H.; COSTA, J. A . Desbaste de mudas tipo filhote do abacaxi cv. Pérola - 1. Produção e qualidade do fruto. Revista Brasileira de Fruticultura, Jaboticabal, v.23, n. , $2001(?)$

LOPES, N. F.; OLIVA, M. A.; GOMES, M. M. S., SOUZA, V. F. de; CARDOSO, M. J. Crescimento, morfologia, partição de assimilados e produção de matéria seca do feijão (Phaseolus vulgares, $L$.), submetidos a três densidades do fluxo radiante $\mathrm{e}$ dois regimes hídricos. Revista Ceres. Viçosa, MG, v.34, n.192, p.110-124, 1987.

PY, C., LACOEUILHE, J. J.; TEISSON, C. L' ananas: sa culture, ses produits. Paris: G. P. Maisonneuve et Larose et ACCT, 1984. $562 \mathrm{p}$. 
REINHARDT, D. H. A planta e o seu ciclo. In: REINHARDT, D. H., SOUZA, L. F. da S., CABRAL, J. R. S. (Org.). Abacaxi. Produção: Aspectos técnicos. Cruz das almas: EMBRAPA Mandioca e Fruticultura; Brasília, DF: EMBRAPA Comunicação para Transferência de Tecnologia, 2000. p.13-14; il. (Frutas do Brasil, 7)

REINHARDT, D. H. R.; MEDINA, V. M. Crescimento e qualidade do fruto do abacaxi cvs. Pérola e Smooth Cayenne. Pesquisa Agropecuária Brasileira, Brasília, v.27, n.3, p.435-447, 1992.

REINHARDT, D. H.; SOUZA, J. da S. Pineapple industry and research in Brazil. Acta Horticulturae, Wageningen, n.529, p.5771,2000 .

REINHARDT, D. H. R.; COSTA, J. T. A.; CUNHA, G. A. P. da.
Influência da época de plantio, tamanho da muda e idade da planta para a indução floral do abacaxi 'Smooth Cayenne' no Recôncavo Baiano. II. Produtividade e características do fruto. Fruits, Paris, v.42, n.1, p.13-23, 1987.

REINHARDT, D. H.; LIMA, V. P. de; COSTA, J. A. Desbaste de mudas tipo filhote na cultura do abacaxi. Cruz das almas: Embrapa Mandioca e Fruticultura, 2000. 4p. (Comunicado Técnico, 67)

SOUZA, J. da S., SOUZA, L. F. da S. Aspectos socioeconômicos. In: REINHARDT, D. H., SOUZA, L. F.da S., CABRAL, J. R. S. (Org.) Abacaxi. Produção: Aspectos técnicos. Cruz das almas: EMBRAPA Mandioca e Fruticultura; Brasília, DF: EMBRAPA Comunicação para Transferência de Tecnologia, 2000. p.10; il; (Frutas do Brasil; 7) 